\title{
Analysis on Local Compression Bearing Capacity of Reinforced Concrete Corbels Constrained by Prestress
}

\author{
YIN Xinsheng ${ }^{1, a}$, LIU Yang ${ }^{1, b}$, WANG Jing ${ }^{1, c}$ \\ ${ }^{1}$ Green Building Technology Engineering Center , Jilin Jianzhu University , Changchun130118, \\ China \\ ayinxinsheng06@eyou.com, b692844325@qq.com, 'c1071537286@qq.com
}

\begin{abstract}
Keywords: prestress, local compression, corbel, ultimate bearing capacity
Abstract. By using the finite element software ABAQUS to establish the model of industrial workshop corbel, to explore the stress state under local load, and then increase the capacity of corbel by the form of prestressing in corbels' end. According to the stress distribution of the calculation, analysis of corbel's normal working state and the prestressed force constraint condition in different forms comparatively. The results found that prestressing at the end of the corbel can significantly improve the ultimate bearing capacity and crack resistance of middle area. Due to the strong constraints of the prestressing, the steel strands can effectively control the deformation of the corbel in horizontal direction, the corbel crack area from the original central transfer to the upper column bending modulus is smaller, eventually destroyed.
\end{abstract}

\section{Introduction}

In recent years, with the continuous development of China's economy, the industrialization degree become deeper, the number of single-floor factory building are increasing. In order to meet the needs of the market, people's demands on the crane are getting higher and higher. So people increase the capacity requirements of corbel. The corbel is a typical case of the force structure of local compression, and it is also a weak link in structure. Reinforce the corbel column is an effective method of improving the ultimate bearing capacity and the crack resistance, while existing method on strengthening corbel of the bearing capacity and crack resistance transformation is limited. This method could not meet the needs of the project. Therefore, how to effectively improve the bearing capacity of corbel and improve its mechanical properties become an urgent problem to be solved in the contemporary project.

The main failure form of the corbel can be divided into the following categories: (1)bending compression failure (2)diagonal compression failure (3)shear failure (4) local compressing failure ${ }^{[1]}$

To analysis the corbel under local loading bearing capacity, we use the finite element analysis software with a practical project, in order to find out the form of its stress distribution. We take the form of external prestressing reinforcement corbel to explore the improvement of the ultimate bearing capacity.

\section{Model establishment}

Brief introduction. A single storey industrial building column bracket which makes before using. Concrete strength grade is C40. The corbel is $400 \mathrm{~mm}$ thick. Concrete protection layer thickness is 40mm. With HRB400 grade reinforcement, the concrete size and reinforcement are shown in Figure 1.The confined area is $200 \times 400 \mathrm{~mm}$ of the rectangular area. The diameter of the pre-stressed steel strand is $15.2 \mathrm{~mm}$ and the section area of steel strand is $139 \mathrm{~mm}^{2[2]}$. Steel plate size is $600 \mathrm{x} 400 \mathrm{~mm}$, thickness $20 \mathrm{~mm}$. 


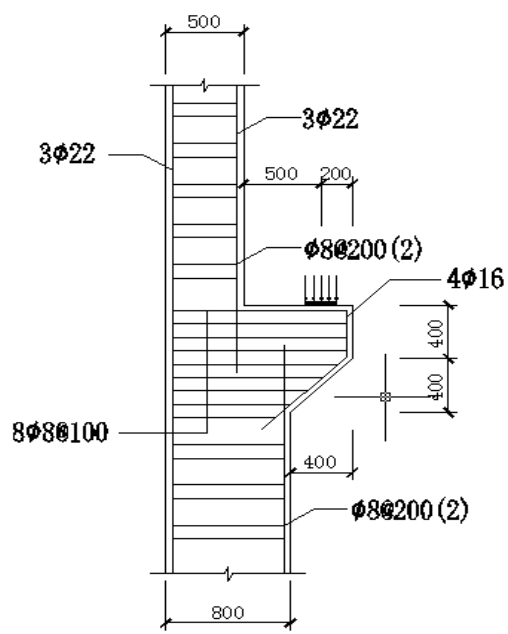

Fig-1 Corbel wit rebar

The establishment of bracket model. In this paper, the ABAQUS finite element analysis software is used to analyze, and then achieve the establishment of cobel model by using CAE function. The corbel and the steel plate using 3 dimensional solid element set. The 3 - dimensional line unit is used for the steel bar and prestressed steel strand. See Table 1 for specific material properties. Because this paper mainly explores the local bearing capacity of corbel, so take the middle part of the corbel to establish. The properties of concrete materials are used in plastic damage model, and the prestress of prestressed steel wire is putting on 1302MPa by cooling method. Take the MPC constraint will bind steel wire end and steel plate together to realize prestress on the corbel constraint. And then load 50MPa on the local bearing region of the corbel. The displacement of the upper and lower columns' surfaces are limited in three directions. The unit size of the model is $0.1 \mathrm{~m}$.

Tab.1 Form of material properties

\begin{tabular}{|c|c|c|c|c|}
\hline & $\begin{array}{c}\text { Modulus of } \\
\text { elasticity } \\
\left(\mathrm{N} / \mathrm{mm}^{2}\right)\end{array}$ & Poisson's ratio & $\begin{array}{c}\text { Yield } \\
\text { strength(MPa) }\end{array}$ & $\begin{array}{c}\text { Expansion } \\
\text { coefficient }\end{array}$ \\
\hline Concrete & 32500 & 0.2 & & \\
\hline Steel plate & 210000 & 0.3 & & \\
\hline Rebar & 200000 & 0.3 & 400 & \\
\hline Steel strand & 200000 & 0.3 & 1860 & $1.2 \times 10^{-5}$ \\
\hline
\end{tabular}

Calculation and analysis. The component can meet the standard requirement according to the conventional calculation method. In order to further study the stress characteristics under the prestress constraint, check on the ultimate bearing capacity of the corbel under normal working condition and under the constraint of prestressed steel strand. Then get the stress cloud images and analyse on the calculation results.

Calculation and analysis of ultimate bearing capacity of normal working condition. As shown in Fig-2, Fig-3 and Fig-4, the corbel in normal working condition, when the load is added to $12.96025 \mathrm{MPa}$, located on the left side of the bracket column of concrete tension cracks. And then the corbel is destroyed after reinforcement yielding in tension. It is not difficult to see through the following figure that the corbel will form a region wide "stress zone" along the oblique downward direction of the 

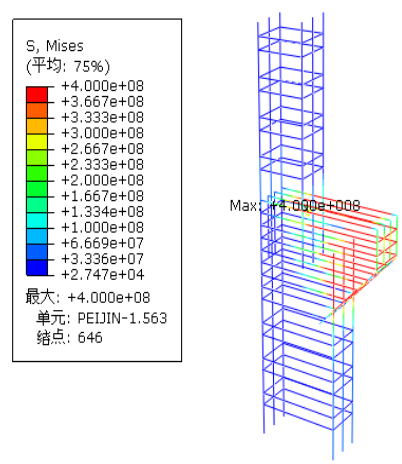

Fig-2 The rebar Mises stress nephogram
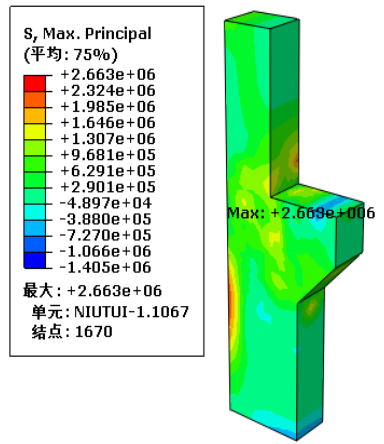

Fig-3 The first principal stress contour of corbel
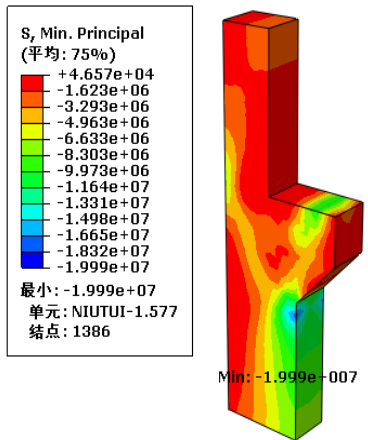

Fig-4 The third principal stress contour of corbel

compression area during the compressing process $^{[3]}$, which is the same as that the space truss model to calculate the triangle theory of column corbel. But all the concrete in the maximum compressive stress is located below the inclined corbel. Because of their numerical value which is $19.9 \mathrm{MPa}$ doesn't reach the compressive strength, they are not destroyed. In the first corbel principal stress nephogram, the "compressive stress zone" are almost perpendicular to the direction of a "tension stress zone" at the left side(The first principal stress nephogram of corbel in the central region). The maximum stress of the concrete is $2.663 \mathrm{MPa}$, which is located in the center of the tensile stress zone. At this time has reached the cracking load, the beginning of concrete cracks. Finally, along with the continuous development of the cracks, eventually leading to bracket column loss of bearing capacity and then to be destroyed. Comparison of maximum and minimum principal stress contour shows that, the tensile stress of the upper part of the corbel is much larger than the compressive stress during the corbel subjected to eccentric load.Through the above analysis, the main failure reasons of corbel is not compression failure but concrete cracking .

Calculation and analysis of ultimate bearing capacity of prestressed strand. According to the above conclusions, the bracket column is due to concrete tensile cracks, finally cracks continue to

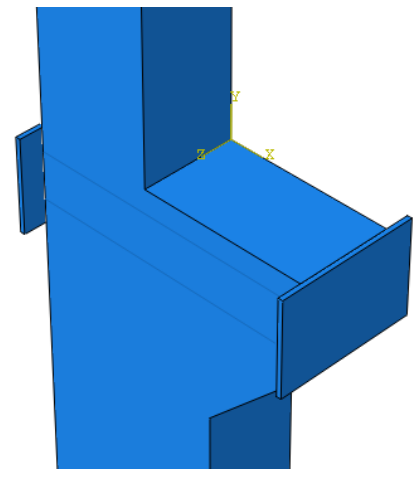

Fig-5 Prestress location map of corbel

carry out the destruction. Now prestressing the corbel horizontal axis constraints, offset the load in pull area of concrete, so as to improve the ultimate bearing capacity of the corbel. Arranged four prestress strand by adopting external prestressing. The pre stress is $1302 \mathrm{MPa}$, with a steel plate whose size is $600 x 400 x 20 \mathrm{~mm}$ anchor the two ends of the corbel,see in Fig-5. 
Calculate the stress contours as shown in Fig-6, Fig-7 and, Fig-8. When the load reached 20.994MPa, most of the steel reached the yield strength. The hooping in the lower part of the corbel yield by tension. And then the concrete of corbel cracks by tension. After gradual loss of bearing capacity, the corbel is destroyed at last.

Through the minimum principal stress nephogram of the corbel, "pressure stress zone" still exists, due to the constraint of the prestress, the pressured concrete in the confined area is changed from
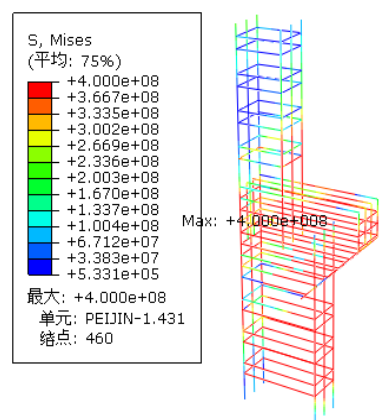

Fig-6 The rebar Mises stress nephogram

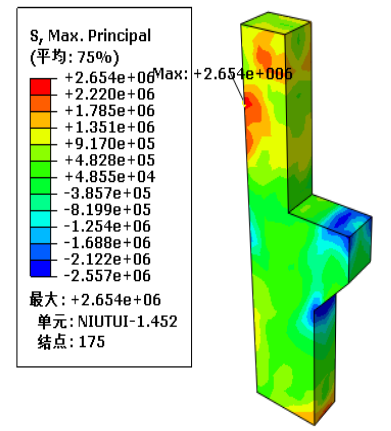

Fig-7 The first principal stress contour of corbel
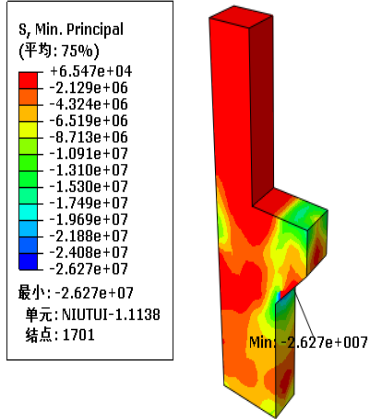

Fig-8 The third principal stress contour of corbel

one direction to two directions. The maximum compressive stress is still below the inclined corbel position. The size is $26.27 \mathrm{MPa}$, and it does not reach its compressive strength, without being destroyed. Through the first principal stress cloud of corbel can be seen, because the position of load eccentricity, the corbel is bent by stress. The left side of the corbel is under tensile stress. With the load increasing, the tensile stress which in the left side concrete of the corbel to increases the cracking load. Finally cracks, so as to gradually be destroyed. Due to the structure of corbel, the geometric dimensions of the cross section of the lower column are larger than that of the upper column, which makes the flexural modulus of lower column of the corbel greater than that of upper column. So its cracking position is located on the upper column rather than the lower column. And the middle part of the corbel due to prestressing restraint effect, changing the the original stress state, the central region of the concrete stress is uniform. The original "pull stress belt" also basically disappeared. Because prestressed offset part of the tensile stress in the corbel and improve the bearing capacity and crack resistance concrete in confined region. The effect of enhance is obvious.

\section{Conclusions}

Through the above analysis can be drawn: in the case of the prestressing, the ultimate bearing capacity of the corbel is improved from $1036.82 \mathrm{kN}$ to $1679.52 \mathrm{kN}$, which is improved by $61.99 \%$. The "tensile stress zone" disappear after prestressing. Due to the restriction of the prestressing, the tensile stress of middle part is uniform and the crack resistance is improved greatly. Crack position transfer from the original middle area of corbel to the upper region. This is because the corbel effected by eccentric load, there will be strong tensile stress on the left side of the corbel. Because of the larger section of the upper column and non strengthened measures on the upper and lower parts of the corbel, its crack resistance has not been improved. So the upper part of the corbel cracks first. Also the prestressed steel strand change the larger tensile stress form of concrete in the middle part, restraining the horizontal deformation of the corbel effectively. Greatly improves the crack resistance of the corbels, of great help to improve the bearing capacity.

\section{Acknowledgements}

The selection of this thesis comes from the National Natural Science Foundation of China. The foundation number is 51178205 . 


\section{References}

[1] Jinshi GUO, Jushun JIN, Xinling ZHUANG. Wuhan: Jinshi GUO, 2011.332-337(In Chinese)

[2] GB 50010-2010. Code for design of concrete structures[S](In Chinese)

[3] Rong PENG. Structure and calculation of corbel. RAILWY SURVEY AND DESIGN.2008(4):104-109(In Chinese) 